\title{
ON THE QUALITY OF BUILDINGS AND CONSTRUCTION PROJECTS: METRICS AND PROCESS DYNAMICS
}

SUBMITTED: December 2019

REVISED: December 2020

PUBLISHED: May 2021

EDITOR: Bimal Kumar

DOI: $10.36680 /$ j.itcon.2021.011

Gilles THING LEO, Researcher,

University Paris-Est,

Constructability Research Institute (IRC), Ecole Spéciale des Travaux Publics, du bâtiment et de l'industrie; gilles.thingleo@estp.fr

\author{
Ahmed MEBARKI, Professor, \\ University Paris-Est, Laboratory Modeling and Simulation Multi-Scale (MSME UMR 8205/CNRS); \\ ahmed.mebarki@u-pem.fr \\ Francis CLAUDE, Researcher, \\ University Paris-Est, \\ Constructability Research Institute (IRC), Ecole Spéciale des Travaux Publics, du bâtiment et de l'industrie; \\ fclaude@estp-paris.eu \\ Christophe GOBIN, \\ University Paris-Est, \\ Constructability Research Institute (IRC), Ecole Spéciale des Travaux Publics, du bâtiment et de l'industrie; \\ cgobin@estp-paris.eu \\ Rani EL MEOUCHE, Researcher, \\ University Paris-Est, \\ Constructability Research Institute (IRC), Ecole Spéciale des Travaux Publics, du bâtiment et de l'industrie; \\ relmeouche@estp-paris.eu
}

SUMMARY: For any building project, the project management triangle QCT (Quality, Cost, Time) are decisive in the decision-making process. Indeed, better, faster and cheaper remain very important goals in the design of new industrial products in a competitive environment. In this paper, we propose a reference framework to formalize the quality criterion that characterizes a building made during a project. A quality measurement is then defined based on the performance levels of the functions actually provided by a building and the requirements originally formulated by its owner. In addition, a modeling of the building production process is proposed to observe the effects of technical or managerial choices on the expected quality of a new or renovated building. Finally, a representation of the level of performance of each building technical attribute over its life cycle is proposed in order to represent the performance recovery allowed by a renovation operation as a resilience process. In the end of this paper, a section is dedicated to a computational experiment for illustrating the theoretical approach.

KEYWORDS: Building, performance, quality, resilience, process dynamics, closed-loop system

REFERENCE: Gilles Thing Leo, Ahmed Mebarki, Francis Claude, Christophe Gobin, Rani El Meouche (2021). On the quality of buildings and construction projects: metrics and process dynamics. Journal of Information Technology in Construction (ITcon), Vol. 26, pg. 174-192, DOI: 10.36680/j.itcon.2021.011

COPYRIGHT: (C) 2021 The author(s). This is an open access article distributed under the terms of the Creative Commons Attribution 4.0 International (https://creativecommons.org/licenses/by/4.0/), which permits unrestricted use, distribution, and reproduction in any medium, provided the original work is properly cited. 


\section{INTRODUCTION}

Quality is commonly expected all along the phases of a building life cycle. Firstly, during a construction project, the quality, the cost and the time of execution, are the three criteria used to make decision between the various technical options. On the other hand, the successful completion of the activities by the occupants during the use phase relies on the quality of the building.

Regarding a construction project, the literature shows that the cost and time criteria are widely treated and there is a consensus on their modeling and their measurements, contrary to the quality of a building (Love, Holt, Shen, Li, \& Irani, 2002) (Lyneis \& Ford, 2007) (Parvan, Rahmandad, \& Haghani, 2012) (Irumba, Kerali, \& Wilhelmsson, 2010) (Nasirzadeh, Afshar, \& Khanzadi, 2008) (Minami, Madnick, \& Rhodes, 2008). The cost (C) and the time (T) are modeled by two continuous quantitative variables usually expressed with monetary units for cost and days, weeks or months for the time. On the other hand, there is no consensus on the qualitative or quantitative quality of a building: there is no scale of values, nor objective indexes. On this point, it is the respect or not to the legislation in force which are the two states mainly taken into account and measured. The expression of quality as a quantitative variable raises the problem of its multidimensional description and its aggregation contrary to cost and time.

As a consequence, the risk is that the justification for the technological choices is established on the basis of individual and subjective references from the project's stakeholders who do not share the same interests, and without a consensus on a quality index. However, with the data quality, cost and time index, the subsequent use of a multi-criteria choice model would make possible to select an optimal option (Chen, Okudan, \& Riley, 2010) (Ebrahimian, Ardeshir, Zahedi Rad, \& Ghodsypour, 2015) (Hijazi, Alkass, \& Zayed, 2009) (SK Kim \& Song, 2009). For a project, without a multilateral consensus between the owners, the architect and the contractors, on the type of the quality index (qualitative or quantitative), its multidimensional description and measurement, the evaluation of constructive alternatives remains ambiguous (see Table. 1). Indeed, the quality is commonly described by the project actors and users with qualitative spoken terms: the quality of the building is "poor", "good" or "very good" for example. But a "good" quality for one stakeholder could be seen as a "poor" quality for another one. As a result, this qualitative description brings subjectivity contrary to cost and time criteria which are described with quantitative data and then free from any ambiguity.

TABLE. 1: Example of a decision on a constructive option

\begin{tabular}{|l|l|l|}
\hline & Option 1 & Option 2 \\
\hline Quality & $?$ & $?$ \\
\hline Time & 200 days & 180 days \\
\hline Cost & $2500 \mathrm{k} €$ & $2400 \mathrm{k} €$ \\
\hline
\end{tabular}

Therefore, in order to establish a consensus on the characterization of a quality, we propose in this paper to model it as an index to obtain an objective quantification. At this point we need to define some concepts that will be used further:

- Function: functionality provided by a building as a service for the users. For example "Providing a room temperature that permits working during summer" is a possible function.

- Dimension: physical unit that is used to measure the performance level of a function. For example " ${ }^{\circ} \mathrm{C}$ (degree Celsius) is the dimension in which room temperature can be measured.

- Performance level: Numerical level associated with the dimension of a function. For example, the performance level of providing a room temperature can be "25"

- Attribute: Association of a dimension and a performance level for characterizing a function.

Then, given the fact that the building simultaneously provides several functions that can be characterized by performance levels of various dimensions, it becomes relevant to propose a global quality measurement system based on the attributes of these functions and on the requirements set out in the contracted specifications of the project. Many attempts to quantify quality appear in the literature, but essentially concern the quality of execution of a task according to a budget and a time deadline and not the quality seen as a level of performance based on the attributes of the functions delivered by the building (Babu, AJG \& Suresh, 1996), (Khang \& Myint, 1999) (Kim JY, Kang, \& Hwang, 2012) (Liberatore \& Pollack-Johnson, 2009). 
In addition, during the use phase, when a function delivered by the building no longer provides a sufficient level of performance, a renovation project is required to recover performance and an adequate level of quality. In France, the economic effect of the non-quality of buildings amounts on average to $3 \%$ of the initial cost of building construction (AQC, 2016). In addition to this, there are the environmental and social effects such as the increase in energy consumption and the decrease of the comfort of users operating in buildings. This observation is in favor of a better characterization of the quality of the buildings in order to optimize its maintenance over time and its recovery when it is necessary. Then it appears that the modeling of the building production process is a prerequisite in order to describe the dynamics of obtaining a performance according to the resources allocated and the possible disturbances of the production process. (D Rwelamila \& W Savile, 1994) proposes a modeling of the production process using a formal system with a feedback loop to cope with the project disturbances. Based on this approach and the definitions exposed after Table. 1, a prospective quantification of the performance level for each function of a building is proposed. In this way, the global performance level of a building can be represented throughout its entire life cycle in order to drive a maintenance policy.

The article breaks down into three sections. (i) The definition of a performance measurement depending on a building technical attribute $\left(\theta_{\mathrm{i}}\right)$ in order to obtain an objective index taking into account two functions. Firstly, a function of possibility $\mathrm{R}_{\theta}$ (.) allowing to formalize a quantitative functional requirement. Secondly, a density function $\rho_{\theta}($.$) modeling the real values historically obtained for the implementation of a given construction process.$ This approach is seen as the assessment of a builder ability to deliver a building that meets performance requirements. An aggregation of the performance measurements of the technical attributes then makes possible to obtain the quality measurement of the building. (ii) The modeling of the production process of the construction project with a transfer function, by taking into account the potential disturbances and parameters conditioning the achievement of a desired level of performance. A sensitivity analysis is then undertaken based on these parameters. (iii) The representation of a performance level for a technical attribute $\left(\theta_{\mathrm{i}}\right)$ throughout the building lifecycle, by incorporating the transfer function previously defined as a performance recovery function to illustrate the resilience process of a building.

\section{ESTIMATION OF THE QUALITY INDEX (Q)}

\subsection{Prospective estimation of a performance level of a technical attribute $\left(\theta_{i}\right)$}

The estimation of the performance level of a physical attribute $\theta \mathrm{i}$ is the object of this part and is determined from two mathematical functions:

1. A membership function $R_{\theta i}($.$) allowing to modeling a quantitative and mathematical representation$ of the requirement addressing an attribute $i$.

2. A density function $\rho_{\theta i}($.$) gathering the historical values of the attribute \theta_{\mathrm{i}}$ obtained within the former building projects for the implementation of a given constructive process and addressing an attribute $i$.

\subsubsection{Functional requirement modeling by a possibility function $R_{\theta i}($.}

With the convention that 0 and 1 respectively represent the minimum level and the maximum level of satisfaction, the function $\mathrm{R}_{\theta \mathrm{i}}($.$) is defined as a membership function supported by a measurable continuous physical attribute$ $\theta$ such that $R_{\theta}: \theta \rightarrow[0 ; 1]$. An examination of the different measurable physical attributes shows that there are three types of satisfaction profile, the values of each parameter $a, b, c$ and $d$ are given by the contracting authority (see Table. 2).

The bilateral profile is associated with physical attributes like temperature due to the fact that a comfort temperature has to be set between a minimum value (for example $19^{\circ} \mathrm{C}$ ) and a maximum value (for example $27^{\circ} \mathrm{C}$ ). Outside of this range, the user of the building would probably be in discomfort.

The incremental profile is associated with a physical attribute like the surface area because the more the provided surface area is large, the more the user would be pleased for performing his activities. The level of satisfaction drops to 0 under a minimum surface area because the user could not perform any activity in the building, and this level reaches 1 above a maximum value because the user does not need an infinite surface. The same reasoning can be done for the decremental profile but for attributes like energy consumption. 
TABLE. 2: Membership functions for mathematically modeling the functional requirements

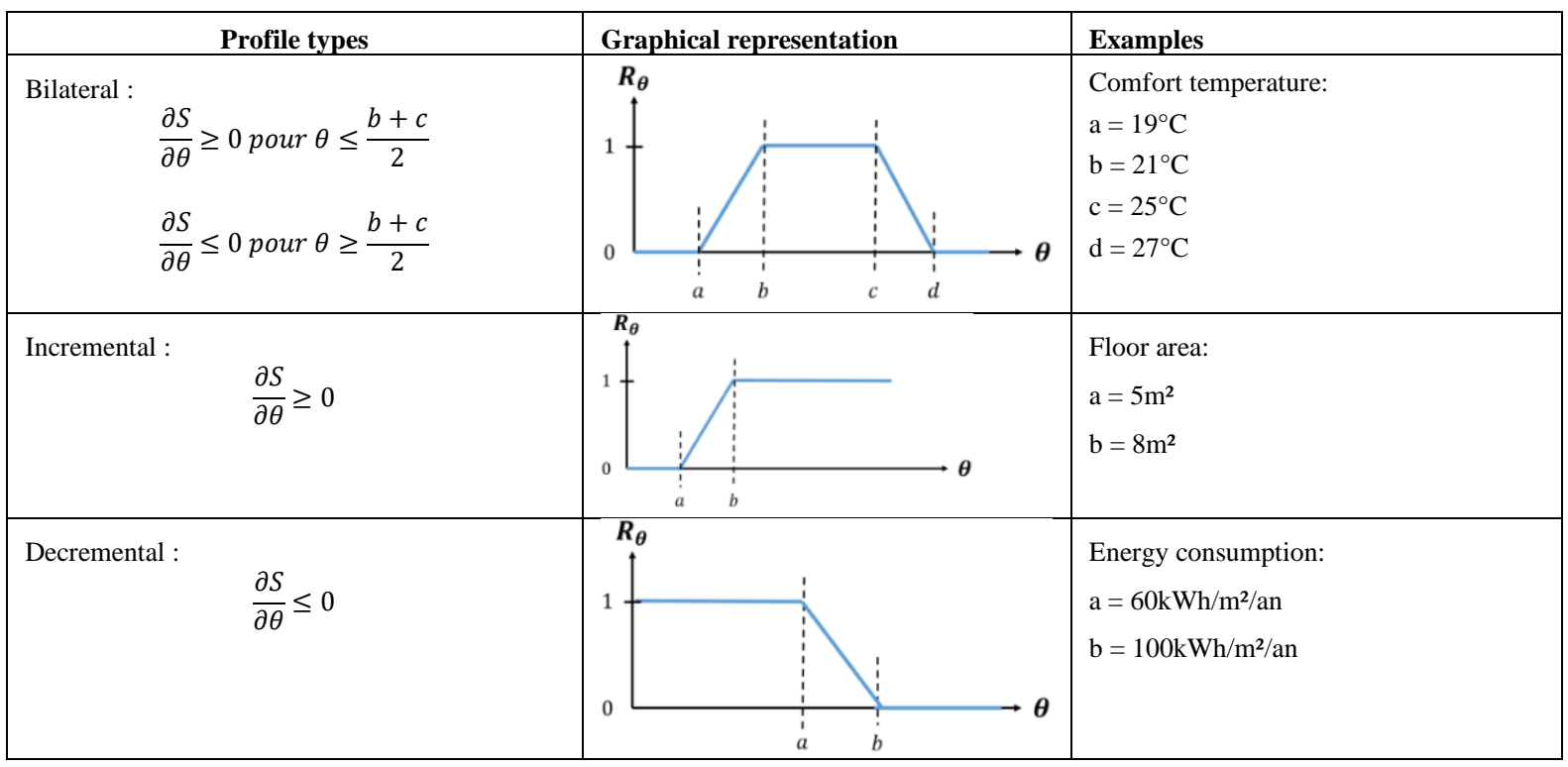

\subsubsection{Modeling of the manufacturer's know-how by a density function $\rho_{\theta}($.}

Each performance type is specified by an attribute with a unit of measurement. For each attribute $\mathrm{i}$ we define a scalar quantity noted $\theta_{i}$. Thus, it is assumed that $\theta_{i}$ is a random variable describing the performance actually implemented as a result of the disturbed production process. The process of appearance of the attribute $\theta_{i}$ is then modeled by a historical statistical distribution. We write $\rho_{\theta_{i}}^{\text {hist }}$ the historical probability density of the attribute $\theta_{i}$. For example, a survey conducted by the Centre Scentifique et Technique du Bâtiment (or CSTB) on the buildings certified by the Haute Qualité Environnementale (or HQE) label, has shown that energy consumption and environmental impacts are characterized by a significant statistical dispersion (CSTB, 2013). Rigorously, such modeling is only relevant for a group of buildings whose construction processes are similar and whose specifications are identical. Thus, a density function $\rho_{\theta_{i}}^{\text {hist }}$ is associated with a constructive option and a performance $\theta_{i}$.

To analyze the feasibility of the present methodology, we make an empirical choice and adopt usual distributions, namely the normal laws $\theta_{i} \sim \mathcal{N}(\alpha, \beta)$ and gamma laws $\theta_{i} \sim \Gamma(\mu, \sigma)$ respectively for symmetric and asymmetric statistical distribution functions. For the rest of this paper, we adopt the notation $\theta$ instead of $\theta_{\mathrm{i}}$ for the sake of simplicity of writing.

\subsubsection{Estimation performance index $P_{\theta}$ as a probability}

Let be $R_{\theta}($.$) and \rho_{\theta}($.$) the function that model respectively the owner's requirement and the know-how of the$ contractor. In order to estimate the performance index $\left(\mathrm{P}_{\theta}\right)$ as the probability of the "quality building" event (see Fig. 1), we calculate the mathematical expected value of the function $R_{\theta}($.$) :$

$$
P_{\theta}=\overline{R_{\theta}}=\int_{-\infty}^{+\infty} \rho_{\theta}(\theta) R_{\theta}(\theta) \mathrm{d} \theta
$$

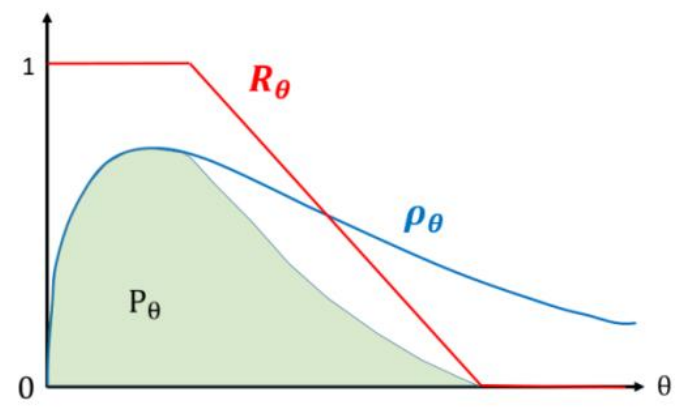

FIG. 1: Performance index related to $\theta$ 
The quantity obtained is bounded in the interval $[0 ; 1]$ and can be seen as a probability. Then we try to maximize this quantity. In addition, the distribution $\rho_{\theta}$ can be constructed from historical statistical data or, without losing any generality, based on prospective hypotheses on the contractor's ability to modify its practices to obtain a distribution with a different shape as we will see later in this article.

\subsection{Definition of attributes and governing quality parameters}

In order to evaluate the "quality building" event, we consider a set of "physical performances" (see Table. 3). It specifies the various functions expected from the building. Depending on the actual performance functions, the building is considered as satisfactory or not.

For the "physical performances", for instance, the event of being satisfactory can be expressed as:

$$
E_{P h y}=f\left(E_{1}, E_{i}, E_{N_{p}}\right) \text { with i=1... } \mathrm{N}_{\mathrm{p}}
$$

Where: $E_{i}=$ Event "Performance attribute satisfaction"; $N_{p}=$ total number of performance attributes, see for example the set of attributes $\left\{E_{S p a}, E_{A m b}, E_{A t}, E_{A c c}, E_{\text {Sit }}, E_{\text {Pro }}, E_{\text {Aest }}\right\}$ indicated in Table. 1 , where $\mathrm{N}_{\mathrm{p}}=7$ i.e. ( $E_{N_{p}}=E_{\text {Aest }}$ ) for the ordered set; $f($.$) is the theoretical combination of the elementary events that governs the$ "physical performance".

TABLE. 3: Performance parameters

\begin{tabular}{|l|l|l|}
\hline Component & Example of sub-component $\boldsymbol{\theta}$ & Notation \\
\hline Space & High ceiling, Floor area & Spa \\
\hline Ambience & Thermal and acoustic comfort & Amb \\
\hline Assets and tools & Number of electric plugs, Power supply level & At \\
\hline Accessibility & Door width, Lifts capacity & Acc \\
\hline Site & $\begin{array}{l}\text { Quantity of carbon dioxide released, } \\
\text { Quantity of used water }\end{array}$ & Sit \\
\hline Protection and capacity & Bearing capacity against extreme loads (earthquakes, wind) & Pro \\
\hline Aesthetics & $\begin{array}{l}\text { Colors of the walls, Total dimensions of the building and their } \\
\text { relative ratios }\end{array}$ & Aest \\
\hline
\end{tabular}

For the list shown in Table. 3, the event "Manager satisfaction", can therefore be expressed as:

$$
E_{M}=f_{M}\left(E_{1}, E_{j}, E_{N_{M}}\right) \text { with } \mathrm{j}=1 . . \mathrm{N}_{\mathrm{M}}
$$

where: $\mathrm{E}_{\mathrm{j}}=$ Event "Manager attributes satisfaction"; $\mathrm{N}_{\mathrm{M}}=$ total number of performance attributes and also "sell price attribute". For the present example, the set of attributes $\left\{\mathrm{E}_{\mathrm{Spa}}, \mathrm{E}_{\mathrm{Amb}}, \mathrm{E}_{\mathrm{At}}, \mathrm{E}_{\mathrm{Acc}}, \mathrm{E}_{\mathrm{Sit}}, \mathrm{E}_{\mathrm{Pro}}, \mathrm{E}_{\mathrm{Aest}}, \mathrm{E}_{\mathrm{Sp}}\right\}$ indicated in Table. 3 , where $N_{M}=8$ i.e. $\left(E_{N_{M}}=E_{S p}\right)$ for the ordered set; $f_{M}($.$) : is the theoretical combination of$ the elementary events that govern the "Manager satisfaction".

The relationship $f_{M}($.$) which expresses the "Manager satisfaction" according to the elementary "attributes$ satisfaction" events is a combination of the elementary events. This combination relies on the choice and decision of the "Manager" (i.e. also Owner, Stakeholder and End-user). Actually this combination of elementary events should represent a mix of "union sub-sets" and "intersection sub-sets" (A Mebarki, Valencia, Salagnac, \& Barroca, 2012), (Ahmed Mebarki, Boukri, \& Laribi, 2014), (Ahmed Mebarki et al., 2016), (Ahmed Mebarki, 2017b)(Ahmed Mebarki, 2017a),(Ahmed, Hasan, \& Tahar, 2016), (Bistouni \& Jahanshahi, 2014). The two extreme combinations correspond then to:

- A serial combination so that the "Manager" is "satisfied" as soon as any of the elementary attributes is satisfactory. The corresponding "satisfactory combination" is then:

$$
E_{M}=\bigcup_{j=1}^{\mathrm{j}=\mathrm{N}_{M}} E_{j}
$$


- A parallel combination so that the "Manager" is "satisfied" only in the case that all the elementary attributes are satisfactory. The corresponding "satisfactory combination" is then:

$$
E_{M}=\bigcap_{j=1}^{\mathrm{j}=\mathrm{N}_{M}} E_{j}
$$

Due to the lack of available data about the satisfaction of the "Manager", the two extremes limits of the probability of satisfaction can then be derived as follows, in case of distinct or independent elementary events:

- For the serial combination, the probability of "satisfactory combination" event is:

$$
P\left(E_{M}\right)=1-\prod_{i=1}^{N}\left(1-P\left(E_{i}\right)\right)
$$

- For the parallel combination, the probability of "satisfactory combination" event is:

$$
P\left(E_{M}\right)=\prod_{i=1}^{N} P\left(E_{i}\right)
$$

Where: $\mathrm{N}=$ number of elementary events governing the "satisfactory event", i.e. $\mathrm{N}=\mathrm{N}_{\mathrm{M}}$ for the case of the manager and $\mathrm{N}=\mathrm{N}_{\mathrm{P}}$ for the case of the physical performance.

Then, let be the quality index defined as $\mathrm{Q}=P\left(E_{M}\right)$.

\section{OPTIMIZATION OF THE EXPECTED PERFORMANCE LEVEL OF AN ATTRIBUTE $\Theta$}

The interest of the works exposed is to maximize the expected level of performance $P_{\theta}$ considering the attribute $\theta$, see $\S 2$ 2.1.3. Formally, this is equivalent to:

1. Move the center of the function $\rho_{\theta}($.$) to the interval where R_{\theta}($.$) reaches its maximum values.$

2. Tighten the function $\rho_{\theta}($.$) around its center by decreasing its variance.$

On a building project, maximizing $P_{\theta}$ by limiting the variance of $\rho_{\theta}($.$) for a given target value, is equivalent to$ master the construction processes. The opposite approach consisting in reshaping the function $R_{\theta}($.$) is possible$ by degrading the level of the requirements of the building owner to match the know-how of the contractor, but it goes against the technical progress and the compliance with the functional requirements initially expressed. Then, the second option is not the best solution. Setting a target value is easy, but monitoring the variance around it is not. This is why in the paper, an approach is developed to model this variance by considering the dynamics of the production process of a construction project. The dynamics presented take into account contextualized parameters in terms of technical and organizational choices on a project. (Thing Leo et al, 2018)

\subsection{Modeling of the variance of a performance $\theta$ : contribution of the close-loop systems theory.}

Any activity performed with a purpose can be represented as a transformation of an incoming work material into an outgoing work material. Then it comes that an activity can be seen as a formal system $S$ defined by an equation like $f(I, O, V)=0$ where $I$ is an input signal, $O$ an output signal and $V$ a vector of state parameters characterizing the system $S$ (see Fig. 2).

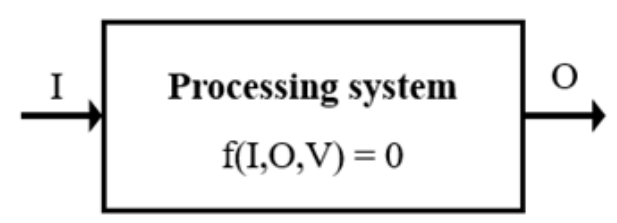

$$
\begin{aligned}
& f: \text { transfer function } \\
& I: \text { input value of parameter } \theta \\
& O: \text { output value of parameter } \theta \\
& V: \text { vector of parameters describing the } \\
& \text { state of the processing system }
\end{aligned}
$$

FIG. 2: Simplified model of a processing system 
Following that assumption, it is possible to refer to the modeling framework of the closed-loop systems used especially in the field of electronic control systems. (Esmaili, Li, Xie, \& Isom, 2018; Gao et al., 2018; Wang, Su, Zhao, \& Zhou, 2018). This modeling framework allows us to consider a feedback loop in order to minimize the gap between the output and the input signals. The formalism used is graphic and can be expressed into a mathematical equation called "transfer function". The same reasoning is still valid for the activities of a construction site. For example, after an operator has completed a task, he checks the conformity of the work and makes a corrective action if necessary. Here we observe a phenomenon of feedback on a microscopic scale of the production process, and which could be replicated on a larger scale.

The advantage of this formalism is that the modulation of the output signal with respect to the input signal, can be expressed with two main factors: (i) the internal organization of the modeled system and (ii) the disturbances influencing the system (see Fig. 3).

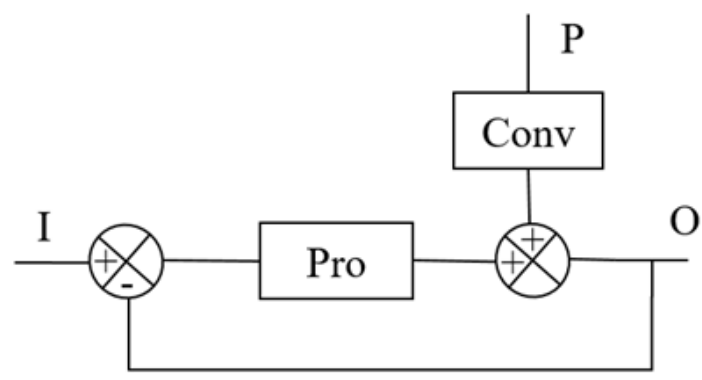

\author{
$I:$ input signal \\ $O$ : output signal \\ $P$ : perturbation signal \\ Pro: primary process \\ Conv : impact converter
}

Transferfunction: $O=I \frac{\text { Pro }}{1+\text { Pro }}-P \frac{\text { Conv }}{1+\text { Pro }}$

FIG. 3: Graphic formalism of a closed-loop system

A system evolving in an open environment is impacted with disturbances which introduce a gap between its output and its input signals. The effect of these disturbances is globally detected with the degradation of the output signal but the challenge is to quantify their intensity in a contextualized and objective way to guide the choices of decision makers during the project.

To understand this transfer function, two cases must be distinguished:

1. $P=0$, case without disturbance: $O=I \frac{\text { Pro }}{1+\text { Pro }}$

In order to let be $O$ converging to $I$ it is sufficient that the value of Pro become great compared to 1 . In other words, the more the construction process is efficient, the more $O$ is close to $I$.

2. $P=1$, case with disturbance: $\mathrm{O}=\mathrm{I} \frac{\text { Pro }}{1+\text { Pro }}-\mathrm{P} \frac{\text { Conv }}{1+\text { Pro }}$

For a given value of Conv, if Pro is great enough, the effect of the disturbance is attenuated by cancelling the second member while the first tends towards I. Moreover if Conv is weak in front of Pro the disturbance has a negligible effect because the second member tends to zero.

Thus, to obtain an output signal that is as close as possible to the initial input, it is necessary to minimize Conv or maximize Pro. This quantitative formalism allows us to control the result of a production process by sizing its state variables.

\title{
3.2 Adaptation of the closed-loop systems formalism to a construction project
}

By analogy, we can replicate the formalism to any activity in the process of building (see Fig. 4). It is necessary, for this, to inject some information characterizing real situations. This contextualization is concretized firstly with a specific formulation of the Pro block that integrates the resource flow used for the purpose of the process, and secondly, an additional block is added to take into account the skills level of the contractor (Cap) and the complexity of the technical options considered (Cpx).

Pro is a production function that converts the means necessary to the project, noted $m$ (financial, material and human), into an expected output. We suppose that an increasing amount of resource involved leads to a better quality of the output. It is assumed here that $m$ includes all types of resources converted into monetary value. For example, a day late on the schedule of a construction site results in a day of operation in terms of equipment rental, 
labor wages, or possible late penalties. By convention, $m$ is expressed relatively to a reference quantity $m_{0}$ with $M=\frac{m}{m_{0}}$. An additional injection of resources compared to the reference case is expressed by $M>1$.

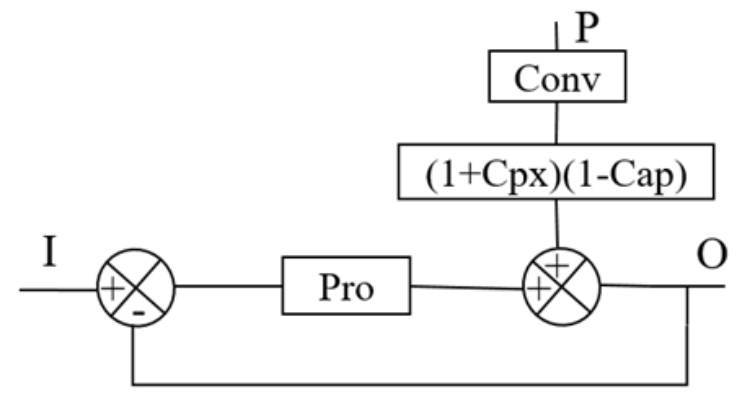

$I$ : expected and contracted value of an attribute of the building

$O$ : effective value of the attribute modulated by the perturbation

$P$ : disturbance caused by an hazard on construction site

Pro: primary process

Conv : impact converter

Cap : skill indicator

Cpx : complexity converter

Transferfunction: $O=I \cdot \frac{P R O}{1+P R O}-P \cdot \frac{\operatorname{Conv} *(1+C P X) \cdot(1-C A P)}{1+P R O}$

FIG. 4: Closed-loop model applied to a construction project

\section{Hypothesis 1:}

Without a well-established relation, we propose, by way of illustration, to adapt the transfer function $T$ by the following transformation:

$$
O=2 I \frac{\alpha}{|\alpha|}\left(\frac{P R O}{1+P R O}+\frac{1}{2}\left(\frac{\alpha}{|\alpha|}-1\right)+k\right)+\frac{\alpha}{|\alpha|} \cdot P \cdot \frac{C O N V \cdot(1+C P X) \cdot(1-C A P)}{1+P R O}
$$

where $P R O=\exp (|\alpha| M)$

Where $\alpha$ is a parameter characterizing a production activity related to a given performance and constructive choice; and $k$ an adjustment parameter to ensure that $O(M=0)=0$.

Consequently, an increasing derivative of the Pro mathematical function is equivalent to a better correction for an additional amount of mean provided to the process. Implicitly, it is assumed, with this modeling of the corrective actions, that the project team is able to effectively correct any deviation from the expected results thanks to their knowledge and their anticipation. Actually, the formulation of Pro therefore depends on the ability to act on the effect of disturbances and thus the type of constructive process handled.

Additionally, we define $C A P$ and $C P X$. Respectively the skill indicator and the complexity indicator. A production activity does not necessarily lead to deviations from the performance targets. This is why the possibility of a neutral balance between the complexity of constructive choices and the skills deployed must be left open. Thus, $(1+C P X) .(1-C a p)$ can mitigate or even cancel the effect of the disturbances if $C A P$ is close to 1 . Conversely, if the implementation teams are not very qualified ( $C A P$ close to 0$)$, the disturbances will be very influential on the performance of the building.

Consequence 1:

$$
\begin{aligned}
& \alpha>0 \Rightarrow O=O_{1}=2 I \cdot\left(\frac{\exp (|\alpha| M)}{1+\exp (|\alpha| M)}+k\right)+P \cdot \frac{C O N V \cdot(1+C P X) \cdot(1-C A P)}{1+\exp (|\alpha| M)} \\
& \alpha<0 \Rightarrow O=O_{2}=-2 I \cdot\left(\frac{\exp (|\alpha| M)}{1+\exp (|\alpha| M)}+k-1\right)-P \cdot \frac{C O N V \cdot(1+C P X) \cdot(1-C A P)}{1+\exp (|\alpha| M)}
\end{aligned}
$$

Hypothesis 2:

$O(M=0)=0$ for $\alpha>0$ and $O(M=0)=2 I$ for $\alpha<0$

In addition, if no resources are allocated to the construction operation $(M=0)$, we can assume that no perturbation is applied on the construction operation $(C O N V=0)$ because there is no construction site. 
Consequence 2:

$$
k=-\frac{1}{2}
$$

Hypothesis 3:

For $M=1, C O N V=0$ and for $\alpha>0$,

$\frac{O}{I}$ is assumed to be upper bounded by 1 so that $O=r I$ with $0<r<1$

Consequence $3 a$ :

$$
\text { for } \alpha>0 \quad|\alpha|=\ln \left(\frac{1+r}{1-r}\right)
$$

For $\mathrm{M}=1, \mathrm{CONV}=0$ and for $\alpha<0$,

$\frac{O}{I}$ is supposed to be inferiorly bounded by 1 so that $O=(2-r) I$ with $0<\mathrm{r}<1$

Consequence $3 b$ :

$$
\text { for } \alpha<0 \quad|\alpha|=\ln \left(\frac{1+r}{1-r}\right)
$$

Hypothesis 4:

When $P=1$, the quantity $P . C o n v$ is the effect of the perturbations on the result $O$. It could be wrapped in a random variable estimated statistically from the historical values of $O$, Pro, $C A P$ and $C P X$. For the sake of simplicity, when there is a disturbance $(P=1)$, we write $C O N V$ instead of P.CONV.

Consequence 4:

$$
\text { For } P=1 \quad C O N V=\left[O-2 I \frac{\alpha}{|\alpha|}\left(\frac{P R O}{1+P R O}+\frac{1}{2}\left(\frac{\alpha}{|\alpha|}-1\right)+k\right)\right] \frac{1+P R O}{(1+C P X) \cdot(1-C A P)}
$$

Hypothesis 5:

The complexity of the building process is seen as an element that amplifies the effect of a disturbance: if a hazard occurs and addresses a complex constructive system, the amount of additional resource due to corrective actions would be significant.

Shannon's entropy is a measurement of complexity used in information theory (Rajaram \& Castellani, 2016). For a source assimilated to a discrete random variable $X$ that can transmit $N$ different symbols, each symbol $x_{i}$ having a probability $P_{i}$ to appear, the entropy $H$ of the source $X$ is defined as:

$$
H(X)=-\sum_{i}^{n} P_{i} \cdot \log \left(P_{i}\right)
$$

An analogy is made here between a source delivering random information and a constructive system delivering a random performance level. Due to the fact that this performance is measured on a continuous scale, the discrete formulation has to be adapted into a continuous formulation. That provides to us a $C P X$ complexity indicator which is specific to a constructive system and for a given performance.

\section{Consequence 5:}

Let $\rho_{\theta}$ be the probability density function of the attribute $\theta$ associated with a given performance. It is proposed here to measure the absolute complexity of implementing a constructive process contributing to this performance by:

$$
\operatorname{Cpx}_{\mathrm{j}}^{*}=-\int_{-\infty}^{+\infty} \rho_{\theta}(\theta) \cdot \log \left(\rho_{\theta}(\theta)\right) \mathrm{d} \theta \quad \text { with } C p x_{j}^{*}>0
$$


In addition, to let be comparable the levels of complexity between various construction processes, a relative complexity index is defined by normalizing the absolute complexity indicator:

$$
C p x_{j}=\frac{C p x_{j}^{*}}{\max _{j} C p x_{j}^{*}} \quad \text { with0 }<C p x_{i} \leq 1
$$

\section{Hypothesis 6:}

Moreover, the measurement of the dispersion of the performance attribute $\theta$ on a sample of buildings made by the same contractor is representative of the mastering of the construction process. Therefore, it is relevant to estimate the skill level of the contractor for an association constructive process - performance.

A skill level is evaluated with respect to a given reference. However, each construction project is singular because the requirements are never identical. Therefore, it is necessary to take as a reference, for each attribute $\theta$, a normative or regulatory value that is noted $N$. For example, for energy consumption, we put $N=50 \mathrm{kWh} / \mathrm{m}^{2}$ for the buildings concerned by the French thermal regulations 2012.

\section{Consequence 6:}

For a constructive process $j$, a production team $k$ and a reference value $N$, we propose to express the index of skill level of the contractor by $\operatorname{Cap}_{j k}$ and to estimate it according to whether $\theta$ is decremental (Eqn 19) or incremental (eqn 20), see Fig. 5 :

$$
\begin{aligned}
& \operatorname{Cap}_{j k}=P(\theta<N)=\int_{-\infty}^{R} \rho_{\theta}(\theta) d \theta \\
& \operatorname{Cap}_{j k}=\mathrm{P}(\theta>N)=\int_{R}^{+\infty} \rho_{\theta}(\theta) \mathrm{d} \theta
\end{aligned}
$$

$\rho_{\theta}$ being defined as a density function, the skill indicator takes its values in the interval $[0 ; 1]$

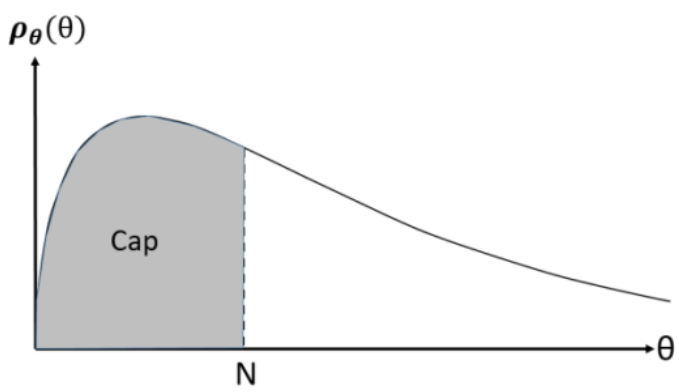

FIG. 5: Case where the skill indicator $\theta$ is decremental

In addition to objectifying the measurement of quality, this methodology finally allows us to question the manufacturer's ability to implement constructive processes according to a given specification. Further developments could be engaged for automatically integrating this approach with a BIM technology as done in (Tafraout and al., 2019).

\section{CONTRIBUTION TO THE RESILIENCE MODEL OF A BUILDING}

\subsection{Contribution of the transfer function within the resilience process}

The modeling of the dynamics of the building process with a transfer function allows us to estimate the level of performance, depending on the resources allocated and the random disturbances influencing the construction project. From a general point of view, this approach can be applied to both new construction and renovation projects. Given an initial level of a performance (for example the energy consumption in $\mathrm{kWh} /$ year of an existing building), the model gives a prospective vision of the level of accessible performances following a renovation (for example insertion of insulating materials in roofing and facades) by considering the resources allocated, the complexity of the chosen construction processes and the skill of the contractor. 
It is in this way that the presented model contributes in modeling the resilience of built systems. Indeed, it was modeled the process of performance recovery by the construction and / or renovation projects. It is one of the key elements of the overall resilience process that can be classically found in literature (Ouyang \& Dueñas-Osorio, 2012) (Yodo \& Wang, 2016) (Bruneau \& Reinhorn, 2006) (Mebarki et al., 2016).

One of the current issues concerning the concept of resilience, particularly in the field of engineering sciences, is to set up a framework to objectively quantify the degree of resilience of a system or its subsystems (components). (Ahmed Mebarki, 2017b) (Mebarki, 2017a) proposes a general quantification approach for resilience based on the example of a metal structure.

In our case, the system studied is a building, characterized by multiple functions which performance level globally decreases in its life cycle. The recovery phases consist of providing external resources to the building (money, work force, construction materials, etc.) through a renovation project over a limited period of time. By assumption, the shape of the loss and recovery function depends on the typology of the system, the types of disturbance considered and the recovery strategy chosen.

By way of illustration, Fig. 6 shows the resilience process of a performance attribute $\theta$ over the entire lifecycle of a built system.

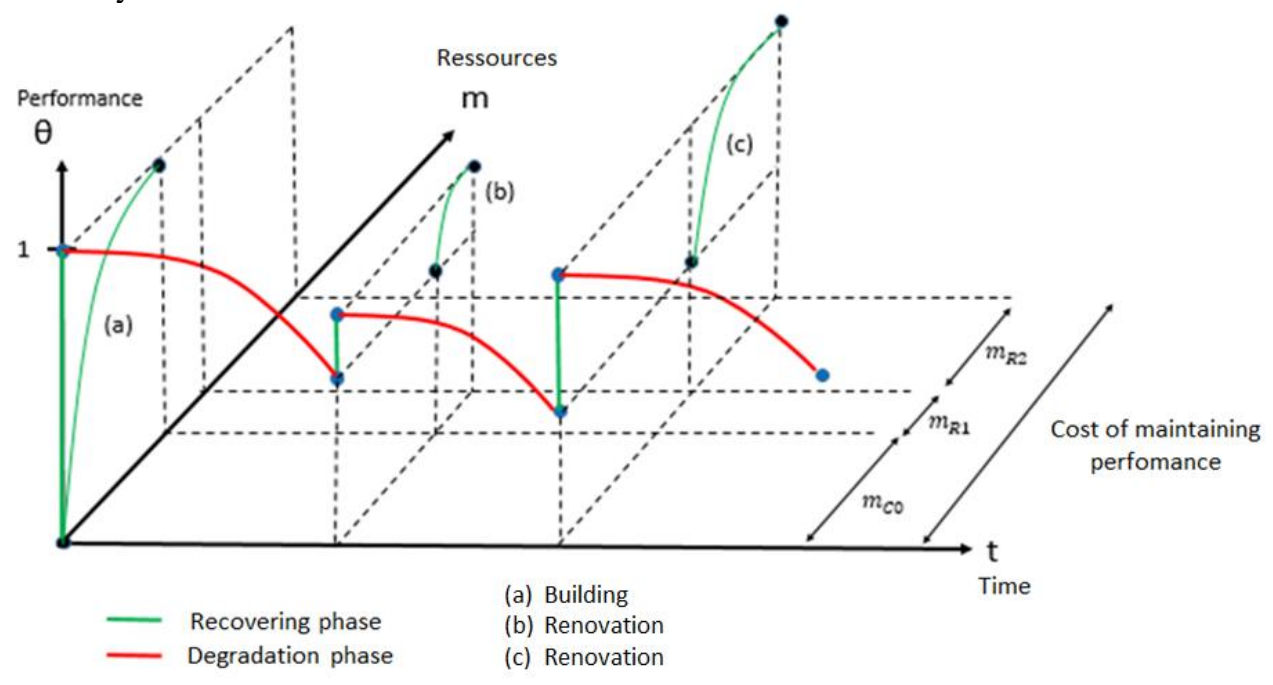

FIG. 6: Resilience process of a built system

The performance recovery phases are faster than to the loss phases, given the limited duration of a construction project versus the lifecycle of a building. (Fig. 7) allows us to visualize the temporality of a recovery phase. $T_{\text {Projet }}$ is the duration of the renovation project and $m_{\text {Projet }}$ is sum of the means provided to the renovation project for the performance recovery attribute $\theta$.

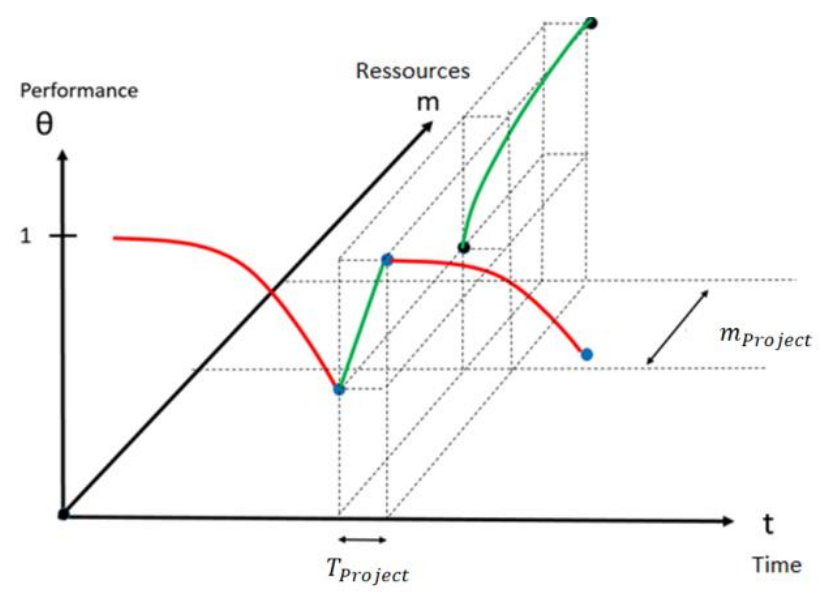

FIG. 7: Detail of the temporality of a recovery phase 


\subsection{Generic modeling of performance dynamics over time}

The generic shape of the resilient process of a built system can then be specified with the formalization of the loss of function. For that purpose, it is proposed to explore potential mathematical functions that can explicitly describe the decrease of the performance attribute $\theta$ over time.

\section{Hypothesis 1:}

Without significant statistical data, it is assumed that the level of performance decreases with time according to an accelerating process (see Fig. 8). Let $T_{0}$ and $T_{v}$, respectively be the beginning and the end of a performance degradation phase. Let $\beta$ be a real number.

For an incremental performance, we define:

$$
\forall t \in\left[T_{0} ; T_{v}\right], \quad \theta(\mathrm{t})=\theta_{0} \cdot\left[2-\exp \left(\beta \cdot\left[\mathrm{t}-\mathrm{T}_{0}\right]\right)\right]
$$

For a decremental performance, we define:

$$
\forall t \in\left[T_{0} ; T_{v}\right], \quad \theta(\mathrm{t})=\theta_{0} \cdot\left[\exp \left(\beta \cdot\left[\mathrm{t}-\mathrm{T}_{0}\right]\right)\right]
$$

In both cases $\theta\left(T_{0}\right)=\theta_{0}$

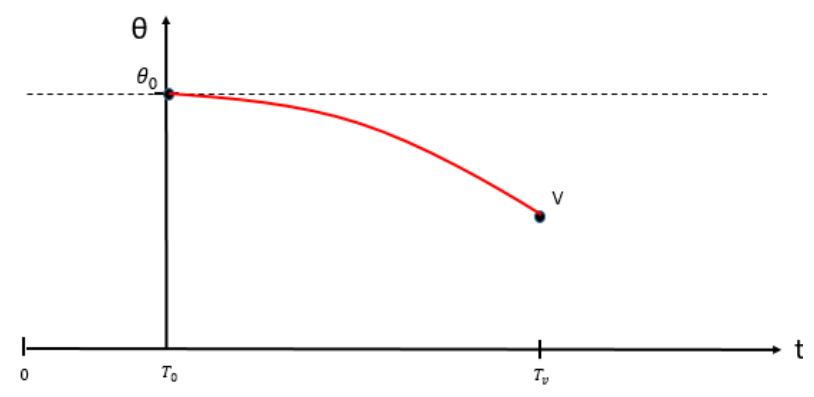

FIG. 8: Degradation process in case of an incremental performance

\section{Hypothesis 2:}

Let be $\mathrm{v} \in[0 ; 1]$. In order to constrain the performance curve to pass through the coordinate point $\left(\mathrm{T}_{\mathrm{v}} ; \mathrm{v} \theta_{0}\right)$, an affine component is added to the previous expression.

For an incremental performance, we define:

$$
\forall t \in\left[T_{0} ; T_{v}\right], \quad \theta(t)=\theta_{0}\left[2-\exp \left(\beta \cdot\left[t-T_{0}\right]\right)\right]+A \cdot t+B \quad \text { with } \theta\left(T_{v}\right)=v \theta_{0}
$$

For a decremental performance, we define:

$$
\forall t \in\left[T_{0} ; T_{v}\right], \quad \theta(t)=\theta_{0} \cdot\left[\exp \left(\beta \cdot\left[t-T_{0}\right]\right)\right]+C \cdot t+D \quad \text { with } \theta\left(T_{v}\right)=(1+v) \cdot \theta_{0}
$$

\section{Consequence 2 :}

For an incremental performance, the addition of the limit conditions in $\mathrm{T}_{0}$ and $\mathrm{T}_{\mathrm{v}}$ gives:

$$
\left\{\begin{array}{c}
A \cdot T_{0}+B=0 \\
\theta_{0}\left[2-\exp \left(\beta \cdot\left[T_{v}-T_{0}\right]\right)\right]+A \cdot T_{v}+B=\theta_{0} \cdot v
\end{array}\right.
$$

We can deduce:

$$
\left\{\begin{array}{c}
B=-A \cdot T_{0} \\
A=\frac{\theta_{0} \cdot v-\theta_{0} \cdot\left[2-\exp \left(\beta \cdot\left[T_{v}-T_{0}\right]\right)\right]}{\left(T_{v}-T_{0}\right)}
\end{array}\right.
$$


Thus we obtain the following formulation for an incremental performance undergoing a degradation process in normal use:

$$
\forall t \in\left[T_{0} ; T_{v}\right], \quad \theta(t)=\theta_{0} \cdot\left[2-\exp \left(\beta \cdot\left[t-T_{0}\right]\right)\right]+\frac{\theta_{0} \cdot v-\theta_{0} \cdot\left[2-\exp \left(\beta \cdot\left[T_{v}-T_{0}\right]\right)\right]}{\left(T_{v}-T_{0}\right)} \cdot\left(\mathrm{t}-T_{0}\right)
$$

For a performance decremental, we obtain as well :

$$
\forall t \in\left[T_{0} ; T_{v}\right], \quad \theta(t)=\theta_{0} \cdot\left[\exp \left(\beta \cdot\left[t-T_{0}\right]\right)\right]+\frac{\theta_{0} \cdot(1+v)-\theta_{0} \cdot\left[\exp \left(\beta \cdot\left[T_{v}-T_{0}\right]\right)\right]}{\left(T_{v}-T_{0}\right)} .\left(\mathrm{t}-T_{0}\right)
$$

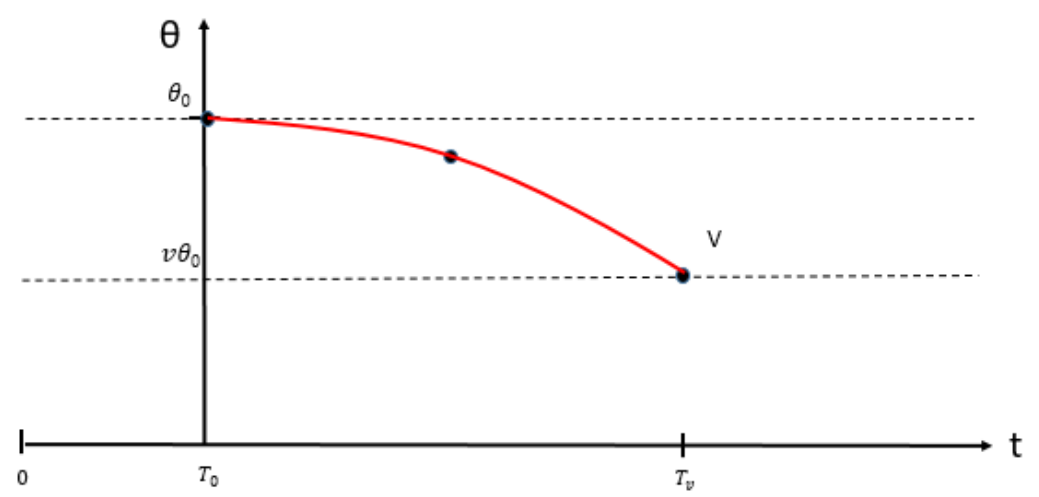

FIG. 9: Degradation process in the case of a performance incremental

The parameter $\beta$ influences the curvature of the loss curve (see Fig. 9). Thus, for $\beta=0$, we would obtain a straight line. In the presence of statistical data of the performance level over time, the determination of the parameter $\beta$ can be made by adjustment using the least squares method, for example. No estimate of this variable could be made for this article due to lack of data available.

\section{Hypothesis 3 :}

The degradation process includes random events (damages) which produce discontinuous performance losses. Let $\Delta \theta$ be the intensity of the incident. The sign of $\Delta \theta$ depends on the incremental or decremental type of the performance.

\section{Consequence 3 :}

For an incremental performance, when a damage appears at $T_{p}$ :

$\forall t \in\left[T_{0} ; T_{p}\left[, \quad \theta(t)=\theta_{0} \cdot\left[2-\exp \left(\beta \cdot\left[t-T_{0}\right]\right)\right]+\frac{\theta_{0} \cdot v-\theta_{0} \cdot\left[2-\exp \left(\beta \cdot\left[T_{v}-T_{0}\right]\right)\right]}{\left(T_{v}-T_{0}\right)} \cdot\left(t-T_{0}\right)\right.\right.$

$$
\left.\forall t \in] T_{p} ; T_{v}\right], \quad \theta(t)=\theta_{0} \cdot\left[2-\exp \left(\beta \cdot\left[t-T_{0}\right]\right)\right]+\frac{\theta_{0} \cdot v-\theta_{0}\left[2-\exp \left(\beta \cdot\left[T_{v}-T_{0}\right]\right)\right]}{\left(T_{v}-T_{0}\right)} \cdot\left(t-T_{0}\right)-\Delta \theta
$$

For an decremental performance, when a damage appears at $T_{p}$ (see Fig. 10):

$$
\begin{gathered}
\forall t \in\left[T_{0} ; T_{p}\left[, \quad \theta(t)=\theta_{0} \cdot\left[\exp \left(\beta \cdot\left[t-T_{0}\right]\right)\right]+\frac{\theta_{0}(1+v)-\theta_{0}\left[\exp \left(\beta \cdot\left[T_{v}-T_{0}\right]\right)\right]}{\left(T_{v}-T_{0}\right)} \cdot\left(t-T_{0}\right)\right.\right. \\
\left.\forall t \in] T_{p} ; T_{v}\right], \\
\theta(t)=\theta_{0} \cdot\left[\exp \left(\beta \cdot\left[t-T_{0}\right]\right)\right]+\frac{\theta_{0}(1+v)-\theta_{0}\left[\exp \left(\beta \cdot\left[T_{v}-T_{0}\right]\right)\right]}{\left(T_{v}-T_{0}\right)} \cdot\left(t-T_{0}\right)+\Delta \theta
\end{gathered}
$$




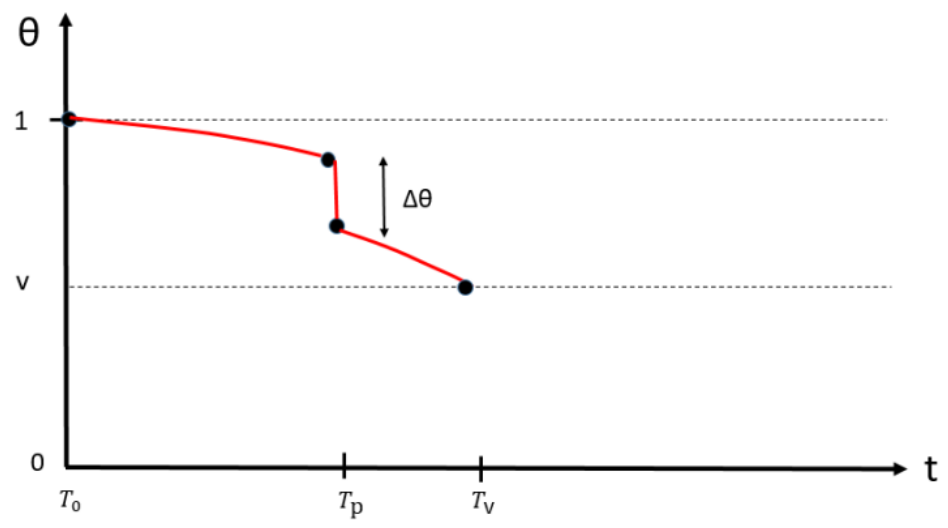

FIG. 10: Degradation process in the case of an incremental performance when damage appears

The occurrence of damage and the degradation due to the normal use of the built system reduce the performances. In order to keep the building at an acceptable level of performance, recovery processes need to be planned. These are renovation projects, for example. However, it is not always possible to recover all the performances at an acceptable cost. For example, following an earthquake, the damage to the supporting structure of a building can involve heavy work in a matter of duration and cost. The owner may then decide to renounce to the renovation and proceed with the demolition of the building, if it is more relevant. In this case, the mechanical performance of the structure would have fallen below a threshold of non-recoverability: it becomes more financially acceptable to demolish than to repair.

Thus, the existence of thresholds allowing the characterization of the level of a performance over time and triggering a performance recovery procedure is postulated. These thresholds are determined by arbitration (owner or consensus of stakeholders among the construction authorities) in relation to the amount of resource to be mobilized to bring the built system back into a window of use at least acceptable to the owner and the users of the building.

\section{COMPUTATIONAL EXPERIMENT}

In order to illustrate the previous theoretical approach, this section contains a computational experiment. For the sake of simplification, a single performance is considered: the air tightness of a building. Then if several performances were considered, the global aggregation is performed as shown at section 2.2. The air tightness of a building is measured in $m^{3} h^{-1} m^{-2}$ like an air leakage rate. The more the leakage rate is low, the more the air tightness is good. This is why air tightness is considered as a decremental attribute.

Let be $\theta: t \rightarrow\left[\mathrm{T}_{0} ; \mathrm{T}_{1}\right]$ the portion of curve that describe de degradation of the air thickness $\theta$ of a building (see Fig. 11). Let be $t$ the age in number of years of the building, $\mathrm{T}_{0}$ the starting point of the life cycle of the building where $\theta$ is optimal $\left(\theta_{0}=0.6 \mathrm{~m}^{3} \mathrm{~h}^{-1} \mathrm{~m}^{-2}\right)$, and $\mathrm{T}_{1}$ an observation time where $\theta$ has increased by $200 \%$. That means $\theta$ value is $\theta_{1}=1.8$ and $v=2$ according to Eqn 28 . This curve is given by setting $T_{0}=0, T_{1}=10$ and $\beta=0,1$. The curve is realistic and describes a usual degradation of the air tightness of a building.

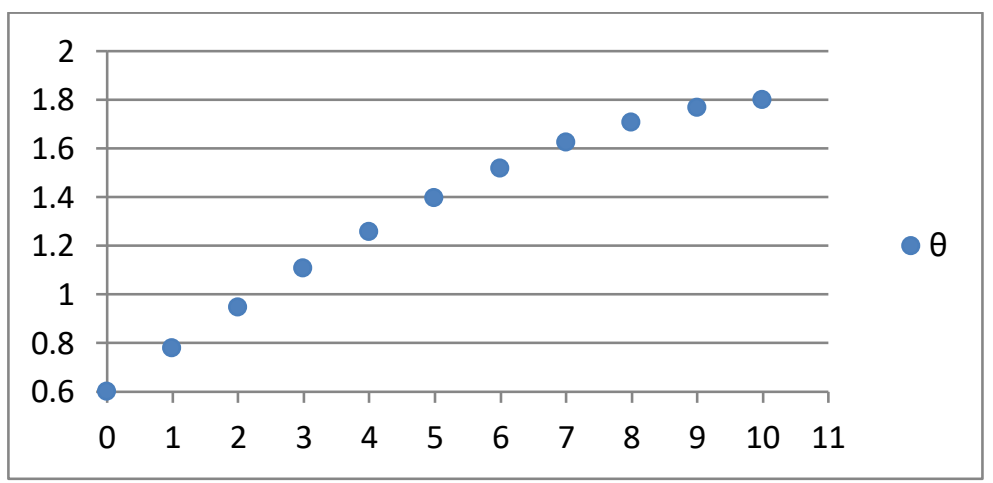

FIG. 11: Degradation curve of the building air tightness $\theta: t \rightarrow\left[T_{0} ; T_{1}\right]$ 
Let be $\mathrm{R}_{\theta}: \theta \rightarrow[0 ; 1]$ the decremental membership function associated with the air tightness and introduced at section 2.1.1. The more leakage rate is low, the more the satisfaction is high (see Fig. 12). According to the notations adopted in 2.1.1, a is the value below which the satisfaction is maximal and $\mathrm{b}$ the value above which the satisfaction is minimal. For the illustration we set $\mathrm{a}=1 \mathrm{~m}^{3} \mathrm{~h}^{-1} \mathrm{~m}^{-2}$ and $\mathrm{b}=2 \mathrm{~m}^{3} \mathrm{~h}^{-1} \mathrm{~m}^{-2}$.

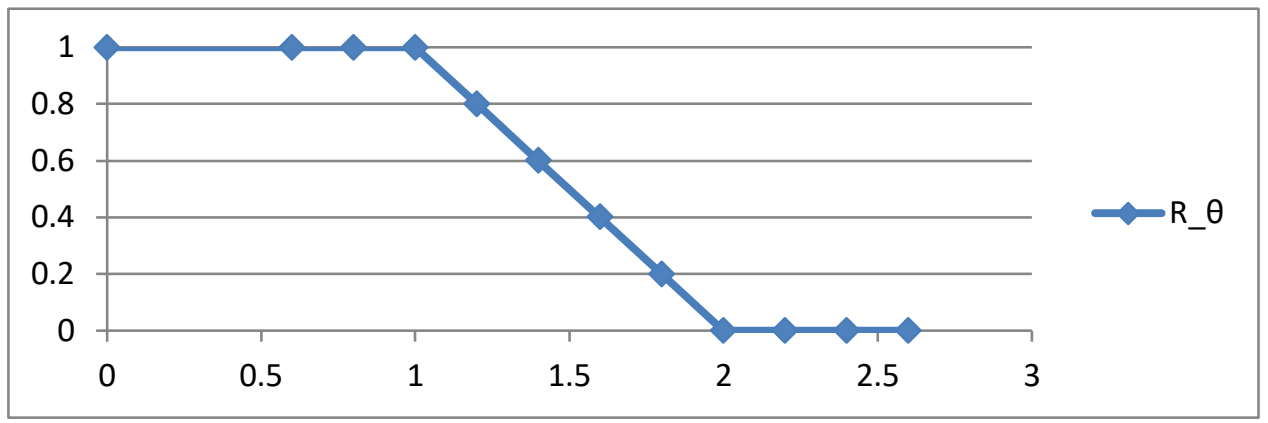

FIG. 12: Curve of the decremental membership function $R_{\theta}: \theta \rightarrow[0 ; 1]$ associated with air tightness

By applying $R_{\theta}($.$) to \theta($.$) it comes the following curve that shows the decreasing evolution of the air tightness$ performance $\mathrm{P}_{\theta}: t \rightarrow[0 ; 1]$ (see Fig. 13)

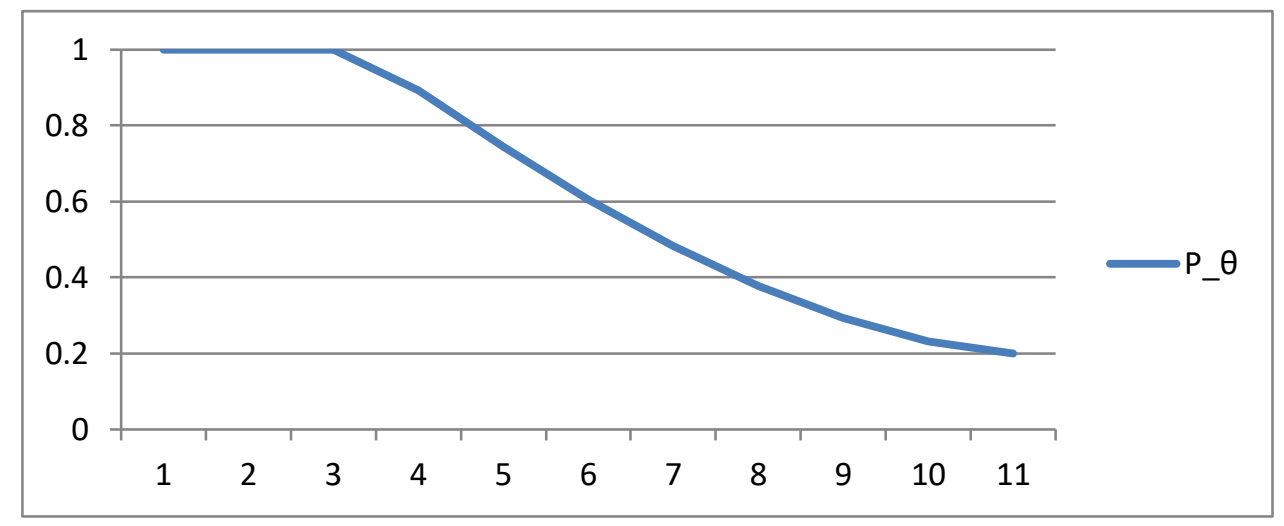

FIG. 13: Curve of the decreasing evolution of the air tightness performance $P_{\theta}: t \rightarrow[0 ; 1]$

At $t=T_{1}=10$ years, we suppose that a renovation operation is planned. The expected result of this operation is a decrease of the air leakage rate and consequently an increase of the air tightness performance. The next step is the estimation of the increase of performance.

By gathering the data from (CSTB, 2013) a statistical distribution for the air tightness of HQE certified buildings has been set by using maximum likelihood estimation. The given distribution is then modeled by a gamma law, $\gamma\left(\mathrm{k}_{1}, \mathrm{k}_{2}\right)$ with the parameters $\mathrm{k}_{1}=1.763$ and $\mathrm{k}_{2}=1.430$, and noted $\rho_{\theta}$ (see Fig. 14). This statistical distribution gives us an historical vision of the complexity of the technical solutions used in the past concerning the air tightness (noted $\mathrm{CPX}_{\mathrm{ref}}$ ) and the mean know-how, or the mean capacity, of the manufacturers (noted $\mathrm{CAP}_{\text {ref }}$ ). According to (Eqn 17) and (Eqn 19), CPX $\mathrm{ref}=1.84$ and, $\mathrm{CAP}_{\text {ref }}=0.23$.

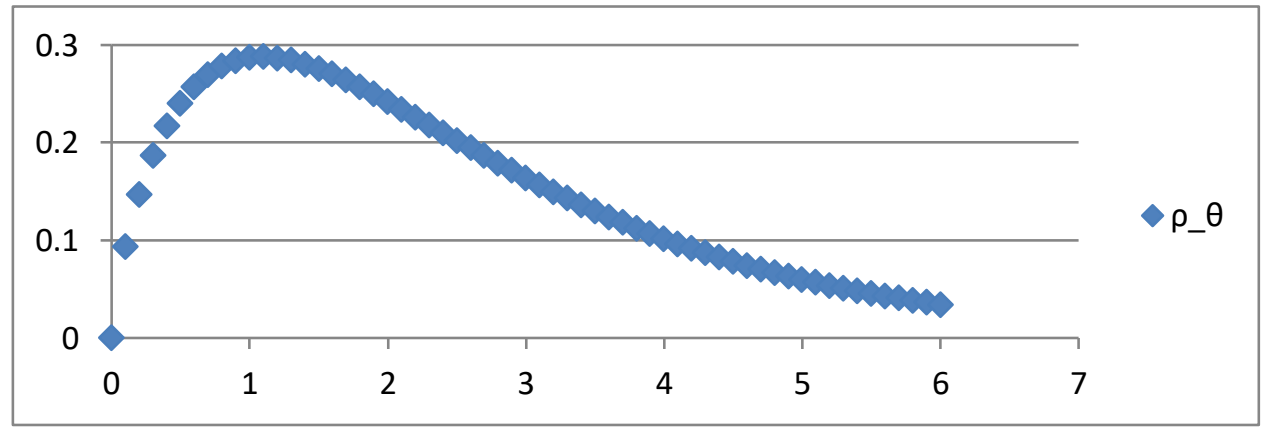

FIG. 14: Statistical distribution of $\theta$, noted $\rho_{\theta}$ 
Additionally the equation (Eqn 8) has to be calibrated by estimating the parameter $\alpha$. For that purpose we apply the equation (Eqn 13) assuming $r=0.95$. It means that there is a tolerance of $5 \%$ between input requirement I and output $O$. As a result $|\alpha|=3.664$ and $\alpha=-3.664$ because air tightness is decremental.

Using the distribution (see Fig. 14) it's possible to obtain a randomly computed array of values for $\theta$. Then, the (Eqn 14) gives for each value of $\theta$, the associated value of the perturbation CONV that caused the deviation from the input value I.

In order to estimate the expected value of $\theta$ after the renovation operation we apply the formula (Eqn 8) on each randomly computed value of CONV. Otherwise, we set $\mathrm{CPX}=\mathrm{CPX}_{\mathrm{ref}}$ if we assume that the same technology is used to perform the air tightness; $\mathrm{CAP}=0.85$ if we assume that a manufacturer with very good skills is contracting for the renovation operation; $\alpha=-3.664$ as we found out previously; $M=1$ if we assume that the same amount of resource is used as usual for this type of operation. After computing the randomized $\theta$ values it is possible to estimate the mean value $\bar{\theta}=1.3$.

If $\mathrm{T}_{2}$ is the date of the end of the renovation operation, the curve $\theta: t \rightarrow\left[\mathrm{T}_{0} ; \mathrm{T}_{2}\right]$ can be established by adding the expected state of the air tightness at the end of the renovation operation (see Fig. 15)

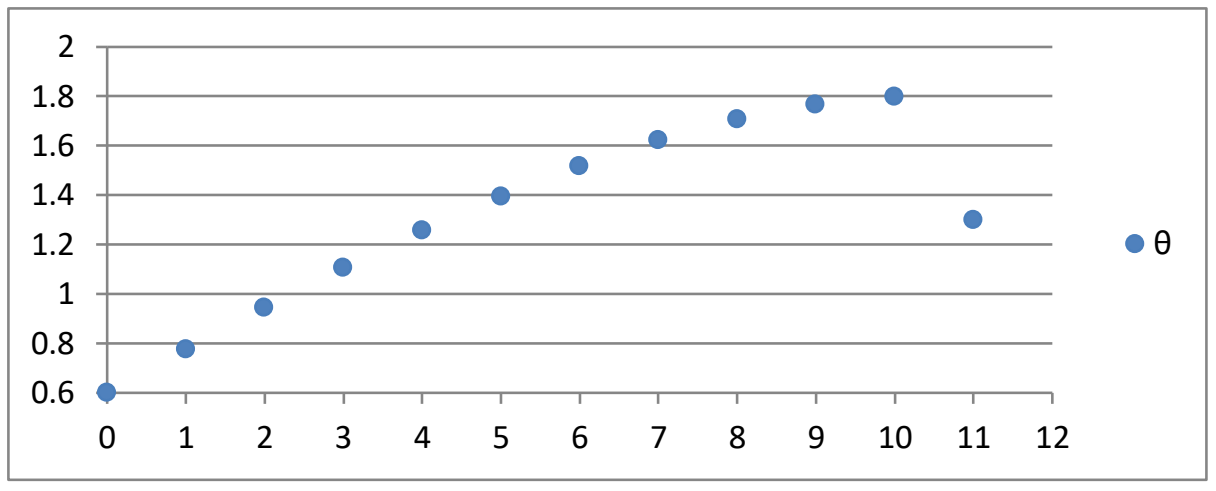

FIG. 15: Probable decrease of air leakage rate after the renovation operation

And then by applying $R_{\theta}($.$) to \theta($.$) it comes the following curve that shows the performance recovery induced$ (see Fig. 16)

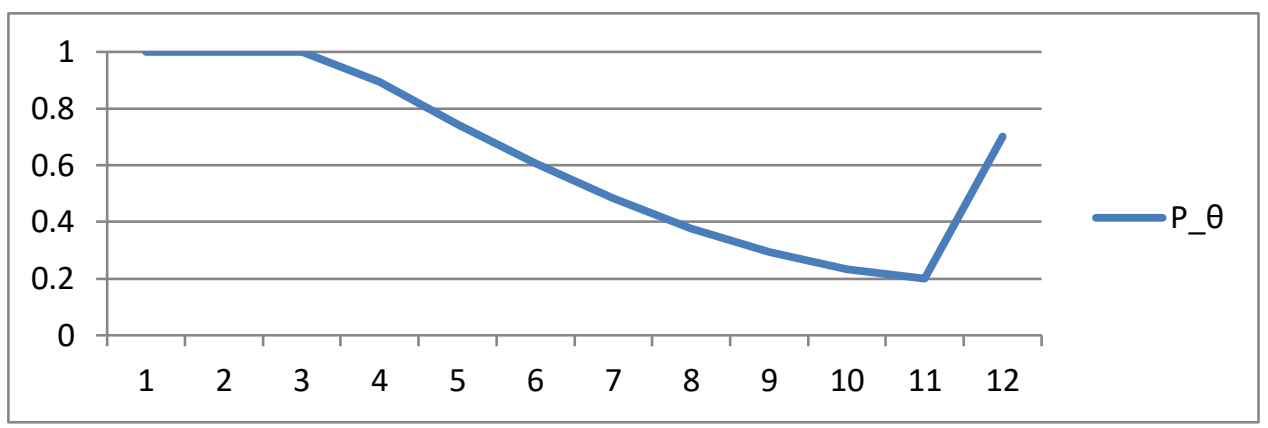

FIG. 16: Performance recovery

This computational experiment performed from realistic data involved a single variation of the level of skills from the manufacturer contracting in the project. But there are many other ways to modulate the intensity of the performance recovery. The index CPX could be useful to discriminate two technical options by evaluating the effect of their complexity on the level of performance. The amount of resource M deployed can be discussed to justify the frequency of renovation operations during the lifecycle of the buildings. All these possibilities would be fully exploited if real data were available.

\section{CONCLUSION}

In conclusion, the decision criterion "Quality" commonly mentioned from the operational and academic point of view on building construction projects has been quantified in this paper. This work prepares to a multilateral 
consensus among actors in the industrial sector of construction. Quantification of the quality criterion is based on two stages. First, the estimation of a performance indicator in the form of probability for each technical attribute linked to the functions provided by the building. This indicator is then obtained by the convolution of two mathematical functions respectively representing a functional requirement and the know-how of the manufacturer. Secondly, the aggregation of these probabilities at the building scales to obtain a numerical value usable later in the multicriteria decision model. In addition, a probabilistic modeling of the production process using the formalism of closed-loop controlled systems influenced by disturbances, allows us to quantify the effect of technical and managerial decisions on the quality level of the buildings. From this modeling comes the formalization of a transfer function linking the likely performance level of a technical attribute to a set of parameters including the amount of resource allocated, the complexity of the constructive processes, and the level of skill of the manufacturer. Finally, an integration of the previous transfer function allows us to determine the evolution of the performance level of any technical attribute. It is then a contribution to the modeling of the resilience process of a building if assumed that the transfer function is comparable to a performance recovery function. In the end of this paper, a computational experiment is performed from statistical data of building air tightness in order to illustrate the possibilities allowed by the theoretical contribution.

By proposing this new approach based on probabilistic concepts, the main challenge is the collect of data to build the probabilistic distributions and calibrate the mathematical functions. Indeed, the literature provides very few data and the probabilistic expert judgements remain today a good solution for implementing the model. However, this lack of data could be addressed in a sustainable way by introducing new protocols of measurement based on the Internet of Things (Huang et al., 2019). At the scale of a building, the sensors involved in this technology could regularly provide samples of data at regular time intervals. At the beginning of the building life cycle, the initial measured values (e.g. temperatures, air tightness, energy consumption) could contribute to determine the function $\rho_{\theta}($.$) representing the know-how of the contractor (cf. section 2.1), and during the life cycle, the measured values$ could be used to determine the degradation dynamics of the performances (cf. section 4.2). The definition of the measurement protocol appears to be a future research: In order to build probabilistic distributions, is it possible to merge data from two buildings characterized by non-equal attributes (e.g. different geometry or different type of building material)? Which measurement timeframe has to be used to best estimate the degradation dynamics?

Another research direction is opened by the fact that we assumed independency between the performances in order to estimate an aggregated global performance (cf. section 2.2). This hypothesis is not always verified because of the relationships between the performances: for example the air tightness affects the energy consumption due to the thermal dynamics of a building. For that reason further research should be performed to build a multicriteria model that takes into account the interaction between the criteria in order to aggregate the performances mentioned in this paper.

\section{ACKNOWLEDGEMENTS}

The authors are grateful for the financial support provided by the FUI 19 RiD Project Management project. This innovative R\&D project is supported by Region Ile-de-France and Banque Publique d'Investissement (BPI).

\section{REFERENCES}

Ahmed, W., Hasan, O., \& Tahar, S. (2016). Formalization of Reliability Block Diagrams in Higher-order Logic. Journal of Applied Logic, 18, 19-41. https://doi.org/10.1016/j.jal.2016.05.007

AQC. (2016). SYCODES Pathologie 2016. Retrieved from http://www.occitanie.developpementdurable.gouv.fr/IMG/pdf/sycodes_2016_pathologie_1_.pdf

Babu, A.J.G. \& Suresh, N. (1996). Theory and Methodology Project management with time, cost, and quality considerations. European Journal of Operational Research, 88, 320-327. https://doi.org/https://doi.org/10.1016/0377-2217(94)00202-9

Bistouni, F., \& Jahanshahi, M. (2014). Analyzing the reliability of shuffle-exchange networks using reliability block diagrams. Reliability Engineering and System Safety, 132, 97-106. https://doi.org/10.1016/j.ress.2014.07.012

Bruneau, M., \& Reinhorn, A. M. (2006). Overview of the resilience Concept. Proceedings of the 8th US National Conference on Earthquake Engineering, (2040), 2-6. 
Chen, Y., Okudan, G. E., \& Riley, D. R. (2010). Decision support for construction method selection in concrete buildings: Prefabrication adoption and optimization. Automation in Construction, 19(6), 665-675. https://doi.org/10.1016/j.autcon.2010.02.011

CSTB. (2013). Evaluation de la performance environnementale des bâtiments. Définition d'ordres de grandeur. Traitement statistique. Retrieved from http://www.hqegbc.org/wp-content/uploads/2015/09/2013-10HQEPerf_Annexes_Partie2.pdf

D Rwelamila, P., \& W Savile, P. (1994). Hybrid value engineering: the challenge of construction project management in the 1990s. International Journal of Project Management, 12(3), 157-164. https://doi.org/10.1016/0263-7863(94)90031-0

Ding, L., Wang, H., Jiang, J., \& Xu, A. (2017). SIL verification for SRS with diverse redundancy based on system degradation using reliability block diagram. Reliability Engineering and System Safety, 165(114), 170-187. https://doi.org/10.1016/j.ress.2017.03.005

Ebrahimian, A., Ardeshir, A., Zahedi Rad, I., \& Ghodsypour, S. H. (2015). Urban stormwater construction method selection using a hybrid multi-criteria approach. Automation in Construction, 58, 118-128. https://doi.org/10.1016/j.autcon.2015.07.014

Effinergie. (2012). Etanchéité à l'air dans les projets BBC. Retrieved from https://www.effinergie.org/web/images/attach/base_doc/1714/etudesurlapermeabilite.pdf

Esmaili, A., Li, J., Xie, J., \& Isom, J. D. (2018). Closed-loop identification for plants under model predictive control. Control Engineering Practice, 72(May 2017), 206-218. https://doi.org/10.1016/j.conengprac.2017.12.003

Gao, Y. G., Jiang, F. Y., Song, J. C., Zheng, L. J., Tian, F. Y., \& Geng, P. L. (2018). A novel dual closed-loop control scheme based on repetitive control for grid-connected inverters with an LCL filter. ISA Transactions, 74(March 2018), 1-15. https://doi.org/10.1016/j.isatra.2018.01.029

Hijazi, W., Alkass, S., \& Zayed, T. (2009). Constructability assessment using BIM/4D CAD simulation model. In AACE International Transactions (pp. 1-14). Retrieved from http://search.ebscohost.com/login.aspx?direct=true \&db=bth\&AN=48225907\&site=ehostlive\%5Cnhttp://scholar.google.com/scholar?hl=en\&btnG=Search\&q=intitle:Constructability+Assessme $\mathrm{nt}+\mathrm{Using}+\mathrm{BIM} / 4 \mathrm{D}+\mathrm{CAD}+$ Simulation+Model.\#0

Huang, Q. et al. (2019) Rapid internet of things (IoT) prototype for accurate people counting towards energy efficient buildings, Journal of Information Technology in Construction, 24(March 2018), pp. 1-13. doi: 10.36680/j.itcon.2019.001.

Irumba, R., Kerali, A., \& Wilhelmsson, M. (2010). Modelling the Dynamics of Safety on Construction Projects: an Undiscovered Rework Perspective. In Proceedings of the International Council for Research and Innovation in Building and Construction (CIB) (pp. 227-240). Salford Quays, United Kingdom. Retrieved from http://www.irbnet.de/daten/iconda/CIB_DC24351.pdf

Jin, J., Pang, L., Zhao, S., \& Hu, B. (2015). Quantitative assessment of probability of failing safely for the safety instrumented system using reliability block diagram method. Annals of Nuclear Energy, 77, 30-34. https://doi.org/10.1016/j.anucene.2014.11.009

Khang, D. B., \& Myint, Y. M. (1999). Time, cost and quality trade-off in project management : a case study. International Journal of Project Management, 17(4), 249-256. https://doi.org/https://doi.org/10.1016/S0263-7863(98)00043-X

Kim, J. Y., Kang, C. W., \& Hwang, I. K. (2012). A practical approach to project scheduling: Considering the potential quality loss cost in the time-cost tradeoff problem. International Journal of Project Management, 30(2), 264-272. https://doi.org/10.1016/j.ijproman.2011.05.004

Kim, M. C. (2011). Reliability block diagram with general gates and its application to system reliability analysis. Annals of Nuclear Energy, 38(11), 2456-2461. https://doi.org/10.1016/j.anucene.2011.07.013

Kim, S. K., \& Song, O. (2009). A MAUT approach for selecting a dismantling scenario for the thermal column in KRR-1. Annals of Nuclear Energy, 36(2), 145-150. https://doi.org/10.1016/j.anucene.2008.11.034

Liberatore, M. J., \& Pollack-Johnson, B. (2009). Quality, time, and cost tradeoffs in project management decision making. In PICMET '09 - 2009 Portland International Conference on Management of 
Engineering \& Technology (pp. 1323-1329). https://doi.org/10.1109/PICMET.2009.5261996

Love, P. E. D., Holt, G. D., Shen, L. Y., Li, H., \& Irani, Z. (2002). Using systems dynamics to better understand change and rework in construction project management systems. International Journal of Project Management, 20(6), 425-436. https://doi.org/10.1016/S0263-7863(01)00039-4

Lyneis, J. M., \& Ford, D. N. (2007). System dynamics applied to project management. System Dynamics Review, 23(2/3), 157-189. https://doi.org/10.1002/sdr

Mebarki, A. (2017a). Resilience : Theory and metrics - A metal structure as demonstrator. Engineering Structures, 138, 425-433. https://doi.org/10.1016/j.engstruct.2017.02.026

Mebarki, A. (2017b). Safety of atmospheric industrial tanks: Fragility, resilience and recovery functions. Journal of Loss Prevention in the Process Industries, 49B, 590-602. https://doi.org/10.1016/j.jlp.2017.06.007

Mebarki, A., Boukri, M., \& Laribi, A. (2014). Seismic vulnerability : theory and application to Algerian buildings. JOSE, 18, 331-343. https://doi.org/10.1007/s10950-013-9377-0

Mebarki, A., Jerez, S., Prodhomme, G., Reimeringer, M., Mebarki, A., Jerez, S., ... Reimeringer, M. (2016). Natural hazards, vulnerability and structural resilience : tsunamis and industrial tanks. Geomatics, Natural Hazards and Risk, (May). https://doi.org/10.1080/19475705.2016.1181458

Mebarki, A., Valencia, N., Salagnac, J. L., \& Barroca, B. (2012). Flood hazards and masonry constructions : a probabilistic framework for damage, risk and resilience at urban scale. Natural Hazards and Earth System Sciences, 1799-1809. https://doi.org/10.5194/nhess-12-1799-2012

Minami, N. A., Madnick, S., \& Rhodes, D. (2008). A systems approach to risk management. In American Society For Engineering Management Conference Proceedings (pp. 0-7). Retrieved from http://manex.com.au/wp-content/uploads/2013/08/A-Shttps://ic3.mit.edu/wp-content/uploads/200818.pdf

Nasirzadeh, F., Afshar, a, \& Khanzadi, M. (2008). System dynamics approach for construction risk analysis. International Journal of Civil Engineering, 6(2), 120-131. Retrieved from http://ijce.iust.ac.ir/files/site1/user_files_6k93w6/afshar-A-10-393-34-fd76760.pdf

Ouyang, M., \& Dueñas-Osorio, L. (2012). Time-dependent resilience assessment and improvement of urban infrastructure systems. Chaos, 22(3). https://doi.org/10.1063/1.4737204

Parvan, K., Rahmandad, H., \& Haghani, A. (2012). Estimating the impact factor of undiscovered design errors on construction quality. In Proceedings of the 30th International Conference of the System Dynamics Society (pp. 1-16). Retrieved from https://www.researchgate.net/publication/259910580_Estimating_the_impact_factor_of_undiscovered_ design_errors_on_construction_quality/references

Rajaram, R., \& Castellani, B. (2016). An entropy based measure for comparing distributions of complexity. Physica A: Statistical Mechanics and Its Applications, 453, 35-43. https://doi.org/10.1016/j.physa.2016.02.007

Tafraout, S., Bourahla, N., Bourahla, Y., \& Mebarki, A. (2019). Automatic structural design of RC wall-slab buildings using a genetic algorithm with application in BIM environment. Automation in Construction, 106. https://doi.org/10.1016/j.autcon.2019.102901

Thing Leo, G., Claude, F., El Meouche, R., Mebarki, A., \& Gobin, C. (2018). Performances d'usage des systèmes bâtis et aide à la décision : Modélisation des perturbations induites par les projets de construction. Congrès Lambda Mu 21, “Maîtrise des risques et transformation numérique : opportunités et menaces ”, Oct 2018, Reims, France. ffhal-02066547f. https://hal.archivesouvertes.fr/hal-02066547/document

Wang, J., Su, J., Zhao, Y., \& Zhou, D. (2018). Searching historical data segments for process identification in feedback control loops. Computers \& Chemical Engineering, 112, 6-16. https://doi.org/10.1016/j.compchemeng.2018.01.018

Yodo, N., \& Wang, P. (2016). Engineering Resilience Quantification and System Design Implications: A Literature Survey. Journal of Mechanical Design, 138(11), 111408. https://doi.org/10.1115/1.4034223 